\title{
Perancangan Aplikasi Kriptografi Asimetris Dengan Menerapkan Metode Elliptic Curve Cryptography
}

\author{
Eka Indah Sari \\ STMIK Budi Darma Medan, JI. SM.Raja No.338 Sp.Limun Medan, Sumut, Indonesia. \\ Email :ekaindahsari789@yahoo.com
}

\begin{abstract}
Cryptography is one of the sciences used to maintain confidentiality and data security has been developing since ancient Greece. One cryptographic method that is quite reliable, stable and the parent of the popular cryptographic algorithms today is Elliptic Curve Cryptography (ECC). In this case the previous block encryption results are feedback into current block encryption. The trick, the current plaintext block is XORed first with the ciphertext block from the previous encryption, then the XOR results are entered into the encryption function. With ECC mode, each ciphertext block depends not only on the plaintext block but also on the all previous plaintext blocks, Implementation of the Elliptic Curve Cryptography (ECC) algorithm in this study was carried out by using an application built using visual basic programming language. Net 2008. .
\end{abstract}

\section{Kata Kunci : Kriptografi, Elliptic Curve Cryptography (ECC), Keamanan Teks.}

\section{PENDAHULUAN}

Keamanan data merupakan salah satu bagian yang penting pada saat ini.Terutama pada pengguna komputer yang sering menyimpan data yang dimiliki pengguna tanpa terlebih dahulu mempasword ataupun menyembunyikan data tersebut. Salah satu aspek keamanan dalam dokumen konvensional dan digital adalah keaslian. Seperti dokumen konvensional, dokumen digital pun harus terjamin keasliannya, bentuk dan isinya harus sesuai dengan yang dimaksud oleh pembuat.

Pengiriman data atau informasi tanpa dilakukan pengamanan akan beresiko terhadap penyadapan [1]. Untuk mengamankan data-data/informasi tersebut dibutuhkan suatu metode yang dapat membuat data tersebut tidak dapat diketahui oleh orang lain selain orang yang dituju untuk menerima data yang dimaksud. Metode tersebut harus mampu untuk mengamankan data.Untuk melindungi akses data dari pihakpihak yang tidak berkepentingan tersebut [2] maka sangat diperlukan enkripsi dan dekripsi.Agar dapat dilakukan dengan baik, dibutuhkan suatu algoritma untuk enkripsi dan dekripsi.Algoritma/metode yang digunakan adalah Elliptic Curve Cryptography (ECC).

Elliptic Curve Cryptography adalah kriptografi kunci publik. Pada kriptografi kunci publik, masing-masing user atau device mengambil bagian dalam komunikasi yang memiliki pasangan kunci yaitu kunci publik dan kunci private [3]. Hanya pengguna yang cocok yang dapat menggunakan private key yang sesuai, tetapi kunci public yang digunakan disebarkan kepada pihak yang akan mengirimkan data. Dipilihnya ECC Elliptic Curve Cryptography sebagai metode kriptografi untuk proteksi dokumen berdasarkan pada hal-hal berikut:

1. Besarnya field dimana kurva elips berada dapat dipilih sehingga memudahkan implementasi Elliptic Curve Cryptography pada suatu batasan tertentu.

2. Besar kunci yang dihasilkan dengan metode Elliptic Curve Cryptography tidak terlalu besar sehingga tidak membutuhkan banyak memori tambahan.

3. Proses kriptografi Elliptic Curve Cryptography tidak membutuhkan prosesor khusus sehingga bisa mengurangi biaya implementasi.

Agar pembahasan tidak keluar dari pokok bahasan,penulis memberikan batasanbatasan sebagai berikut : Yang dibahas dalam aplikasi kriptografi ini adalah pengamanan data berupa text seperti huruf [10].

\section{LANDASAN TEORI}

\section{$2.1 \quad$ Kriptografi}

Cryptography (kriptografi) berasal dari bahasa Yunani yaitu dari kata crypto yang berarti penulisan secret (rahasia), sedangkan graphein artinya writing (tulisan). Jadi secara sederhana dapat diartikan secret writing (tulisan rahasia). Definisi lain dari kriptografi adalah sebuah ilmu yang mempelajari teknikteknik matematika yang berhubungan dengan aspek keamanan informasi seperti 
kerahasiaan, integritas data serta otentikasi. Menurut terminologinya, kriptogrofi adalah ilmu dan seni untuk menjaga keamanan pesan ketika pesan dikirim dari suatu tempat ke tempat lain. (Doni Ariyus, Pengantar IImu Kriptografi, 2006)

\subsection{Elliptic Curve Cryptography}

The Elliptic Curce Cryptosystem (ECC) diperkenalkan pada tahun 1985 oleh Neal Koblitz dan Victor Miller dari Universitas Washington. Kurva eliptik mempunyai masalah logaritma yang terpisah sehingga sulit untuk dipecahkan.Kriptografi kurva eliptik termasuk sistem kriptografi kunci publik yang mendasarkan keamanannya pada permasalahan matematis kurva eliptik.

The Elliptic Curce Cryptosystem (ECC) diperkenalkan pada tahun 1985 oleh Neal Koblitz dan Victor Miller dari Universitas Washington[7]. Kurva eliptik mempunyai masalah logaritma yang terpisah sehingga sulit untuk dipecahkan.Kriptografi kurva eliptik termasuk sistem kriptografi kunci publik yang mendasarkan keamanannya. Dalam proses enkripsi, pertama-tama dilakukan pembacaan suatu berkaskunci publik yang berisi kurva eliptik $E$, suatu point $P$ yang berada pada $E$, suatu bilangan prima $p \in F p$, dan kunci publik pemakai lain $Q=d^{*}$ P. Kemudian dipilih suatu bilangan random $k \in\{2, \ldots, p-1\}$ yang berubah untuk setiap blok data, dan dihitung $k^{*} Q$ dan $k^{*} P$, selanjutnya berkas data dibaca secara per blok (M) dan dienkripsi dengan cara :

Keterangan :

$$
M^{\prime}=\left[k^{*} P, M \oplus X\left(k^{*} Q\right)\right]
$$

$\mathrm{M}=$ data yang akan dienkripsi (plaintext).

$\mathrm{M}^{\prime}$ = blok data yang telah dienkripsi

(ciphertext).

$\mathrm{k}$ = suatu bilangan random yang akan

digunakan sebagai session key dengan $\mathrm{k} \in$

$\{2, \ldots, p-1\}$

$Q=d^{*} P$

$P=$ suatu point pada kurva $E(F p)$

$X\left(k^{*} Q\right)=$ koordinat $X$ untuk point yang

dihasilkan dari perkalian $k^{*} \mathrm{Q}$.

$M$ di-xor-kan dengan absis point yaitu $k^{*} Q$,

hasilnya berupa string yang lalu ditulis ke

berkas dengan $k^{*} P$ ditambahkan sebelumnya.

Hasil akhirnya secara sederhana dapat dilihat sebagai berikut :

\begin{tabular}{|c|c|}
\multicolumn{1}{|c}{$M_{1}$} & $M_{2}$ \\
\hline$k^{*} P$ & $M \oplus X\left(k^{*} d^{\star} P\right)$ \\
\hline & $M^{\prime}$
\end{tabular}

Keterangan :

M1 : session key.

M2 : Data terenkripsi.

$\mathrm{M}$ : Data yang belum terenkripsi.

M' : Blok data yang telah dienkripsi

(ciphertext).
Proses ini akan terus dilakukan selama data yang dibaca masih ada.

Dalam proses dekripsi, pertama-tama dilakukan pembacaan suatu berkas kunci publik yang berisi kurva eliptik $E$, suatu point $P$ yang berada pada $E$, dan suatu field bilangan prima $p$. Kemudian dibaca ciphertext seperti pada Gambar. 2.4. Lalu dihitung $\mathrm{d}^{*}\left(\mathrm{k}^{*} \mathrm{P}\right)$, dengan $\mathrm{d}$ adalah kunci privat yang dimasukkan oleh pemakai dalam bentuk passphrase, dan $k^{*} P$ berasal dari ciphertext. Satu buah blok data lalu dibaca (M'). Setelah itu dilakukan proses dekripsi untuk memperoleh $\mathrm{M}$, dengan

$\mathrm{M}=\left[\mathrm{M} 2 \oplus \mathrm{X}\left(\mathrm{d}^{*}\left(\mathrm{k}^{*} \mathrm{P}\right)\right)\right]$

M2 di-xor-kan dengan absis point yaitu $d^{*}\left(k^{*} P\right)$ sehingga diperoleh suatu string. Hasilnya (M) lalu ditulis ke berkas. Hasil akhirnya secara sederhana dapat dilihat sebagai berikut :

$$
\frac{\mathrm{M}_{2} \oplus \mathrm{X}\left(\mathrm{d}^{*}\left(\mathrm{k}^{*} \mathrm{P}\right)\right)}{\mathrm{M}}
$$

Keterangan :

M2 : Data terenkripsi.

$M$ : Blok data yang telah didekripsi (plaintext). Proses ini akan terus dilakukan selama data terenkripsi yang dibaca masih ada.

\section{PEMBAHASAN}

Pada proses enkripsi dan depenelitian dengan metode ECC adapun yang menjadi input adalah kunci rahasia (k) dan titik kurva $(\mathrm{x}, \mathrm{y})$. Titik kurva didapatkan dengan menggunakan rumus dan juga secara manual dengan memperhatikan titik $x$ dan y. Sebelum melakukan proses enkripsi dan depenelitian terlebih dahulu ditentukan kunci umum (kP) dan kunci rahasia (kP).

Kunci publik (kP) akan dikirimkan bersama dengan pesan terenkripsi sebagai header yang akan dihitung oleh penerima pesan sebagai titik awal pendepenelitiansan pesan.

\subsection{Tahap-Tahap Enkripsi}

a. Tentukan plaintext

b. Tentukan kunci publik dengan rumus $k^{*}(x, y)$

Kunci rahasia $(k)$

Titik kurva $(\mathrm{x}, \mathrm{y})$

c. Proses

$k^{*}(x, y)=$ kunci publik $(k P)$

Menentukan titik enkripsi $k^{*} k P$ untuk mendapatkan titik absis $\mathrm{x}$.

Pesan diubah dan di xor kan dengan titik $x$ yang menghasilkan pesan terenkripsi. Pesan dikirim dengan ( $k P$ sebagai header, pesan terenkripsi).

d. Output

Pesan terenkripsi/chipertext 


\subsection{Tahap-Tahap Deskripsi}

1. Ambil pesan terenkripsi

2. Masukkan kunci rahasia Kunci rahasia $(\mathrm{k})$

Titik kurva $(x, y)$ didapatkan dari header pesan terenkripsi sebagai $\mathrm{kP}$

3. Proses

Menentukan titik enkripsi $k^{*} k P$ untuk mendapatkan titik absis $\mathrm{x}$.

Menentukan titik awal deskripsi dengan memisahkan header $\mathrm{kP}$ dan pesan.

Hader KP dikalikan dengan $k$ untuk mendapatkan kunci dalam bentuk $(\mathrm{x}, \mathrm{y})$.

Titix $x$ di xor kan dengan pesan terenkripsi untuk mendeskripsikan pesan.

4. Output

Pesan terdeskripsi/plaintext

\subsection{Proses Enkripsi}

1. Plaintext yang akan dienkripsi "STMIKBUDIDARMA"

2. Tentukan kunci publik dengan rumus $k^{*}(x, y)$ dimana $k=$ kunci rahasia dan $(x, y)=$ titik kurva. Titik kurva dapat dipilih secara manual atau dengan rumus persamaan misalnya $y^{\wedge} 2=x^{\wedge} 3+x+1$.

$\mathrm{k}=4 \quad \mathrm{x}, \mathrm{y}=(8,10)$

public key $=(32,40)$

3. Tentukan titik kkP untuk mengetahui absis $x$ sebagai awal enkripsi

$\mathrm{k}^{*} \mathrm{kP}=4^{*}(32,40)$

Titik kkP : $(128,160)$

Selanjutnya titik absisx dari kkP untuk dixor-kan ke pesan.

128 -> 10000000

Tabel 1 Konversi pesan ke integer sesuai format ASCII, kemudian jadikan biner. Selanjutnya di xor dengan absis titik kdP.

\begin{tabular}{|c|c|c|c|c|c|c|}
\hline $\begin{array}{c}\text { Plainte } \\
\boldsymbol{x}\end{array}$ & $\begin{array}{c}\text { Asci } \\
\mathbf{i}\end{array}$ & Biner & xor & Biner & $\begin{array}{c}\text { Asci } \\
\mathbf{i}\end{array}$ & $\begin{array}{c}\text { Chiperte } \\
x t\end{array}$ \\
\hline $\mathrm{S}$ & 83 & $\begin{array}{c}0101001 \\
1\end{array}$ & xor & $\begin{array}{c}1000000 \\
0\end{array}$ & 211 & 6 \\
\hline $\mathrm{T}$ & 84 & $\begin{array}{c}0101010 \\
0\end{array}$ & xor & $\begin{array}{c}1000000 \\
0\end{array}$ & 212 & O \\
\hline M & 77 & $\begin{array}{c}0100110 \\
1\end{array}$ & xor & $\begin{array}{c}1000000 \\
0\end{array}$ & 205 & I \\
\hline I & 73 & $\begin{array}{c}0100100 \\
1\end{array}$ & xor & $\begin{array}{c}1000000 \\
0\end{array}$ & 201 & É \\
\hline K & 75 & $\begin{array}{c}0100101 \\
1\end{array}$ & xor & $\begin{array}{c}1000000 \\
0\end{array}$ & 203 & É \\
\hline
\end{tabular}

4. Output pesan terenkripsi dikirim dengan format (header,pesan) $=(£ \#$ \#, Óôí́Ė $)$.

Header adalah public key.

\subsection{Proses Dekripsi}

1. Chipertext yang akan didapatkan (£\# \#, Óôí́ËÊÂ)

2. pisahkan header dan chipertext Header $=£ \# d \#$ diubah menjadi karakter adalaha 32\#40\# sebagai titik $x, y$ $\mathrm{k}=4$

3. Tentukan titik kkP dengan rumus $\mathrm{k}^{*}$ header untuk mengetahui absis $\mathrm{x}$ dari header

$\mathrm{k}^{*}$ header $=4^{*}(32,40)$

Titik kkP : $(128,160)$

Selanjutnya titik absis $x$ dari kkP untuk di-xor-kan ke pesan.

128 -> 10000000

Konversi pesan ke integer sesuai format ASCII, kemudian jadikan biner. Selanjutnya di xor dengan absis titik kdP. Setelah di xor, rangkai lagi menjadi pesan baru yang terenkripsi:

Tabel 2 Hasil Xor

\begin{tabular}{|c|c|c|c|c|c|c|}
\hline Chipertext & Ascii & Biner & xor & Biner & Ascii & Plaintext \\
\hline$\hat{O}$ & 211 & 11010011 & xor & 10000000 & 83 & 5 \\
\hline$\hat{O}$ & 212 & 11010100 & xor & 10000000 & 84 & $\mathrm{~T}$ \\
\hline$\dot{I}$ & 205 & 11001101 & xor & 10000000 & 77 & $\mathrm{M}$ \\
\hline$\hat{E}$ & 201 & 11001001 & xor & 10000000 & 73 & $\mathrm{I}$ \\
\hline$\ddot{E}$ & 203 & 11001011 & xor & 10000000 & 75 & $\mathrm{~K}$ \\
\hline$\hat{A}$ & 194 & 11000010 & xor & 10000000 & 66 & $\mathrm{~B}$ \\
\hline
\end{tabular}

4. Output pesan terdeskripsi "STMIK"

\subsection{Algoritma Pembangkit Kunci}

Berikut ini adalah algoritma enkripsi:

Procedure algoritma \{

$$
\begin{aligned}
& \text { Input } \begin{array}{r}
\mathrm{k}=\text { secret key } \\
\mathrm{x}=\text { titik kurva } \mathrm{x} \\
\mathrm{y}=\text { titik kurva } \mathrm{y}
\end{array} \\
& \text { output }: \mathrm{pk}=\text { public key } \\
&: \mathrm{kp}=\mathrm{k}\left(\mathrm{x}^{*} \mathrm{y}\right)^{\wedge} 2 \\
& \mathrm{k}=\mathrm{k}\left(\mathrm{x}^{\star} \mathrm{y}\right)
\end{aligned}
$$$$
\text { Proses : } k p=k\left(x^{*} y\right)^{\wedge} 2
$$

\subsection{Algoritma Enkripsi}

Berikut ini adalah algoritma enkripsi:

Procedure algoritma \{

$$
\begin{aligned}
& \text { Input }: \mathrm{t}=\text { plaintext } \\
& \mathrm{k}=\text { secret key } \\
& \mathrm{x}=\text { titik kurva } \mathrm{x} \\
& \mathrm{y}=\text { titik kurva } \mathrm{y} \\
& \text { output }: \mathrm{c}=\text { chipertext } \\
& \mathrm{t}_{\mathrm{i}}=\mathrm{t} \text { xor }(\mathrm{kp}) \text {; } \\
& \mathrm{c}=\mathrm{t}_{\mathrm{i}}
\end{aligned}
$$

Menu utama dapat dikatakan sebagai antar muka (user interface) antara user dan program. Menu utama menampilkan pilihan 
menu yang tersedia pada program. Pada menu utama aplikasi enkrip dan depenelitian tersedia 3 pilihan menu yaitu menu enkripsi untuk memenkripsi pesan yang menghubungkan ke formenkripsi dan menu depenelitianuntuk mengubungkan ke form depenelitian dan menu exit untuk keluar dari program enkripsi dan depenelitian dengan metode eliptic curve crypthography. Berikut gambar untuk tampilan menu utama dapat dilihat pada gambar 1 .

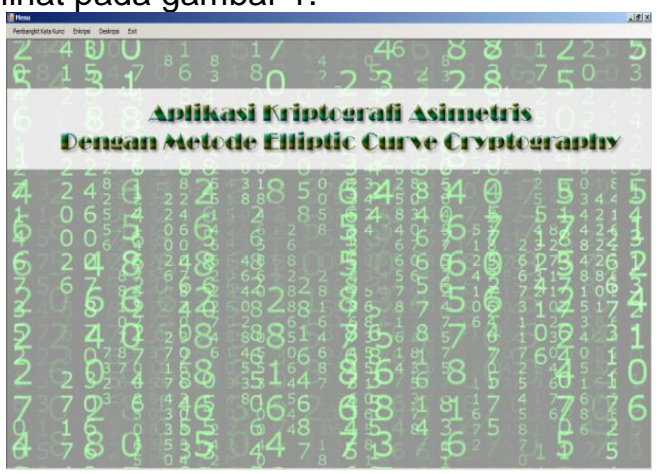

\section{Gambar 1 Menu Utama}

Form pembangkit kata kunci digunakan untuk membangkitkan kata kunci private key yang akan digunakan untuk mendeskripsikan pesan yang diterima dan public key akan digunakan untuk mengenkripsikan pesan yang akan dikirim ke penerima pesan. Berikut gambar untuk tampilan formpembangkit kata kunci dapat dilihat pada gambar 2 .

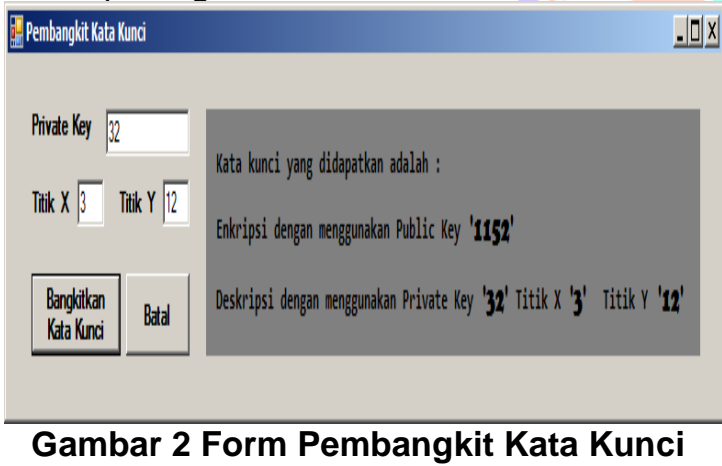

Form enkripsi digunakan untuk mengekripsikan text yang akan dikirim ke penerima. Public key didapatkan dari form pembangkit kunci. Plaintext adalah tempat mengetikkan pesan yang akan dienkripsikan. Hasil enkripsi akan tampil ketika tombol enkrip ditekan. Berikut gambar untuk tampilan formenkripsi dapat dilihat pada gambar 3 .

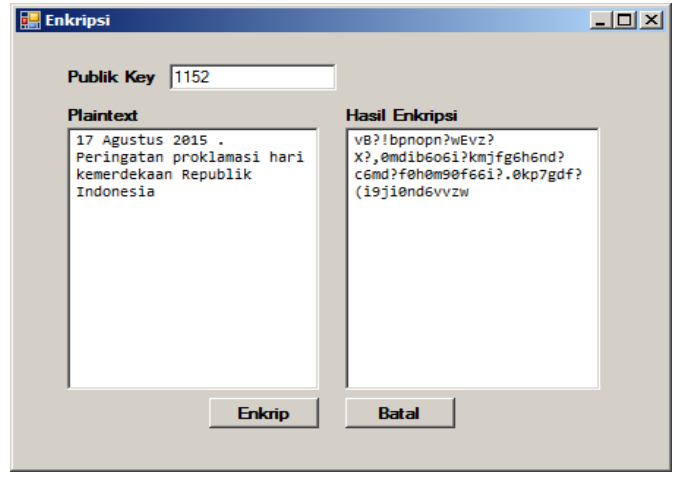

\section{Gambar 3 Form Enkripsi}

Form deskripsi digunakan untuk mendepenelitiankan text yang diterima dari penerima.Private key didapatkan dari form pembangkit kunci. Chipertext adalah tempat mengetikkan pesan yang akan dienkripsikan.Berikut gambar untuk tampilan formdepenelitian pada gambar 4 .

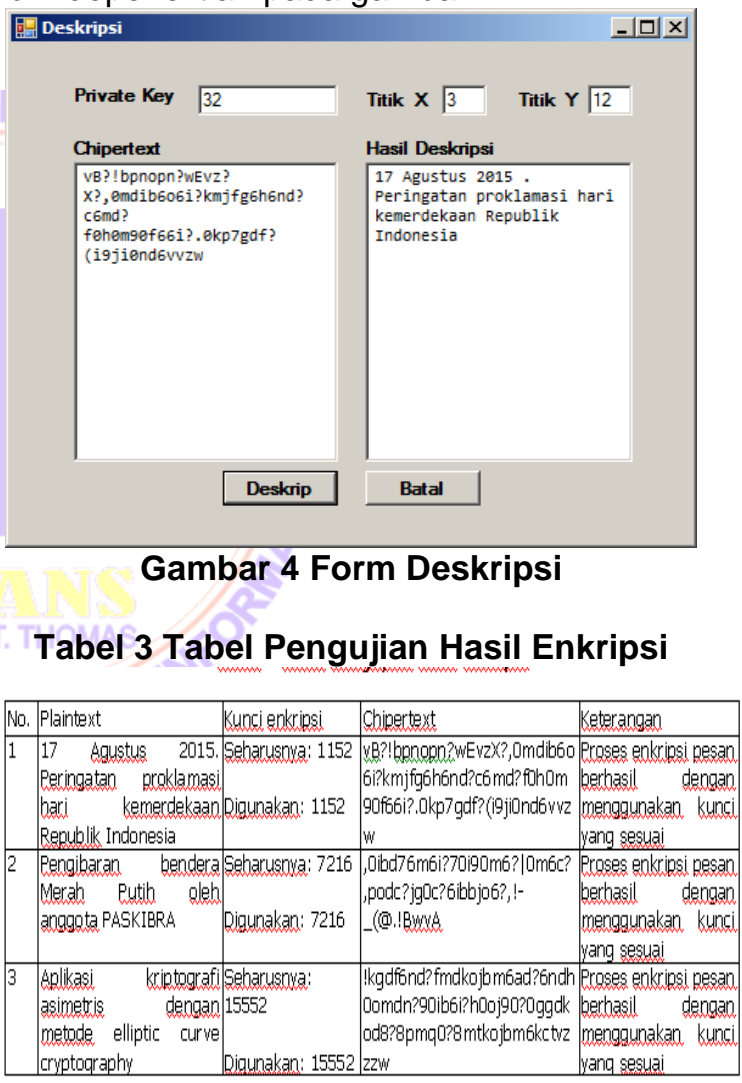

Tabel 4 Tabel Pengujian Hasil Enkripsi 


\begin{tabular}{|c|c|c|c|c|}
\hline No. & Chipertext & Kunci deskripsi & Hasil Deskripsi & Keterangan \\
\hline 1 & $\begin{array}{l}\text { YB?! bpnopp? wE wzX?,0m } \\
\text { dib6o6i? kmjfg6h6nd?c6 } \\
\text { md?foh0m90f66i?,0kp7g } \\
\text { df? (igjiond6wzw }\end{array}$ & $\begin{array}{l}\text { Sebarusova : } \\
\text { Private Key : } 32 \\
x: 3 \text { Y: } 12 \\
\text { Digunakan: } \\
\text { Private Key : } 32 \\
x: 3 \quad Y: 12\end{array}$ & $\begin{array}{l}17 \text { Aqustus 2015. Peringatan } \\
\text { proklamasi bari kemerdekaan } \\
\text { Republik Indonesia }\end{array}$ & 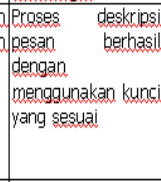 \\
\hline 2 & 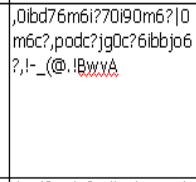 & $\begin{array}{l}\text { Segharusova : } \\
\text { Private Key : } 41 \\
x: 8 \quad y: 22 \\
\\
\text { Digunakan: } \\
\text { Private Key : } 41 \\
x: 6 \quad Y: 22\end{array}$ & - & 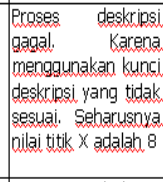 \\
\hline 3 & $\begin{array}{l}\text { !kgdf6nd? fmdkojbm6ad? } \\
\text { 6ndh0omdn?90ib6i?h0oj } \\
\text { 90?0ggdkod8?8pmq0?8 } \\
\text { mtkojbm6kctvzzzw }\end{array}$ & $\begin{array}{l}\text { Selharuspya : } \\
\text { Private Key : } 27 \\
x: 16 \quad \text { Y: } 36 \\
\text { Digunakan: } \\
\text { Private Key : } 27 \\
X: 16 \quad Y: 36\end{array}$ & $\begin{array}{l}\text { Aplikass kriptografi asimetris } \\
\text { dengan metode elliptic curve } \\
\text { cryptography }\end{array}$ & $\begin{array}{ll}\text { Proses } & \text { deskripsi } \\
\text { pesan } & \text { berbasil } \\
\text { dengan } & \\
\text { menggunaakan kunci } \\
\text { yang sesual }\end{array}$ \\
\hline
\end{tabular}

\section{KESIMPULAN}

Ada beberapa kesimpulan yang dapat diambil penulis setelah merancang dan menyelesaikan penelitian ini adalah :

1. Proses enkripsi dan depenelitian dengan menggunakan metode Elliptic Curve Cryptography (ECC). Dilakukan dengan mengkalkulasikan private key dengan titik $\mathrm{x}$ dan titix y untuk mendapatkan public key. Private key digunakan untuk mendepenelitiankan pesan dan public key digunakan untuk mengenkripsikan pesan yang akan dikirim kepada penerima.

2. Untuk mengamankan data teks dapat dilakukan dengan enkripsi dan depenelitian dengan metode Elliptic Curve Cryptography (ECC). Metode ini memanfaatkan perbedaan kunci untuk mengnkripsikan dan perbedaan kunci untuk mendepenelitiankan. Sehingga tidak mudah untuk menebak kunci yang digunakan seandainya pesan diterima oleh pihak lain.

3. Cara merancang aplikasi kriptografi ini yaitu dengan menggunakan Visual Basic .NET 2008. Memanfaatkan tools seperti textbox, button, form, modul.

\section{DAFTAR PUSTAKA}

[1]. Syah Suhatman Surya, "Kamus Komputer". Penerbit Rineka Cipta, Surabaya 2002.

[2]. Kadir Abdul, "Pengenalan Teknologi informasi". Penerbit Andi, Jakarta 2006,

[3]. Arius Doni, "Pengantar Ilmu Kriptografi". Penerbit Andi Publisher,Jakarta 2006.

[4]. Sugiarti $Y$, "Analisis Dan Perancangan Unified Modeling Languange", Penerbit Graha Ilmu, Jakarta 2014.

[5]. Darmayuda Ketut, "Pemrograman Aplikasi Database Dengan Microsoft VisualBasic. Net 2008” "Penerbit Elex Media Komputindo.
[6]. http///id.Wikipedia org/wiki/ASCI (tanggal akses 07 juni 2015).

[7]. Eko Mardianto, Enkripsi Menggunakan ECC, Politehnik Elektronika Negeri Surabaya.

[8]. http://www.elangsakti.com/2013/07/perhi tungan-algoritma-kriptografi-kurvaeliptik-elliptic-curve-cryptographyecc.html.

[9]. Purwadi, Hendra Jaya, Ahmad Calam, Program Studi Komputer, STMIK Triguna Dharma.

[10]. Lamhot Sitorus, Algoritma dan Pemrograman, Andi Offset, Yogyakarta. 2015 